\title{
Institutional guidelines on maternal care and investigations following antepartum stillbirth - a national survey
}

\author{
Dana A. Muin ${ }^{1 *}$, Sabrina Neururer ${ }^{2}$, Veronika Rotter ${ }^{1}$, Hermann Leitner ${ }^{2}$, Stephanie Leutgeb ${ }^{3}$, \\ Peter W. Husslein ${ }^{1,3}$, Herbert Kiss ${ }^{1,3}$ and Petra Kohlberger ${ }^{1,3}$
}

\begin{abstract}
Background: Antepartum stillbirth, i.e., intrauterine fetal death (IUFD) above 24 weeks of gestation, occurs with a prevalence of 2.4-3.1 per 1000 live births in Central Europe. In order to ensure highest standards of treatment and identify causative and associated (risk) factors for fetal death, evidence-based guidelines on clinical practice in such events are recommended. Owing to a lack of a national guideline on maternal care and investigations following stillbirth, we, hereby, sought to assess the use of institutional guidelines and clinical practice after IUFD in Austrian maternity units.
\end{abstract}

Methods: A national survey with a paper-based 12-item questionnaire covering demographic variables, local facilities and practice, obstetrical care and routine post-mortem work-up following IUFD was performed among all Austrian secondary and tertiary referral hospitals with maternity units $(n=75)$ between January and July 2019 . Statistical tests were conducted using $\mathrm{Chi}^{2}$ and Fisher's Exact test, respectively. Univariate logistic regression analyses were performed to calculate odds ratio (OR) with a 95\% confidence interval (Cl).

Results: 46 (61.3\%) obstetrical departments [37 (80.4\%) secondary; 9 (19.6\%) tertiary referral hospitals] participated in this survey, of which 17 (37.0\%) have implemented an institutional guideline. The three most common investigations always conducted following stillbirth are placental histology (20.9\%), fetal autopsy (13.1\%) and maternal antibody screen (11.5\%). Availability of an institutional guideline was not significantly associated with type of hospital, on-site pathology department, or institutional annual live and stillbirth rates. Post-mortem consultations only in cases of abnormal investigations following stillbirth were associated with lower odds for presence of such guideline [OR 0.133 (95\% Cl 0.018-0.978); $p=0.047]$. 26 (56.5\%) departments consider a national guideline necessary.

Conclusions: Less than half of the surveyed maternity units have implemented an institutional guideline on maternal care and investigations following antepartum stillbirth, independent of annual live and stillbirth rate or type of referral centre.

Keywords: Stillbirth, Fetal death, Guideline, Post-mortem work-up

*Correspondence: dana.muin@meduniwien.ac.at

${ }^{1}$ Department of Obstetrics and Gynecology, Division of Feto-Maternal

Medicine, Medical University of Vienna, Waehringer Guertel 18-20,

1090 Vienna, Austria

Full list of author information is available at the end of the article

\section{Background}

Antepartum stillbirth, i.e., intrauterine fetal death (IUFD) above 24 weeks of gestation, occurs with a prevalence of 2.4-3.1 per 1000 live births in Central Europe [1,2]. Due to underlying risk factors, recurrence risk may be as high as 20 -fold in subsequent pregnancies [3]. A detailed 
and standardized work-up following stillbirth is therefore indicated in all cases to detect potential risk factors and define the cause of death $[4,5]$. Medical guidelines and recommendations on clinical practice are usually published by national societies or networks [6]. Guidance on maternal care and investigations following antepartum stillbirth is available from societies as the Royal College of Obstetricians and Gynaecologists (RCOG), the Perinatal Society of Australia and New Zealand (PSANZ) and the American College of Obstetrics and Gynecology (ACOG) [7-10]. The main overarching components in these are the conduction of fetal autopsy, macroscopic and histological evaluation of the placenta and umbilical cord, as well as maternal examinations, such as the KleihauerBetke test, glucose tolerance test, thyroid function test, and screening for infections or thrombophilia. A thorough post-mortem work-up has shown to elucidate the aetiology in up to $90 \%$ of cases and should therefore be an indispensable element in care following antepartum stillbirth.

To date, none of the German-speaking fetal-maternal professional Societies (i.e., Austrian, German, Swiss) have published any official national protocol on care and investigations following stillbirth. Considering the option of local protocols at individual institutions, we, therefore, sought to explore how many Austrian secondary and tertiary referral hospitals with maternity units have implemented an institutional guideline on maternal care and investigation following stillbirth, and which factors night have perpetuated the implementation of such. Lastly, we aimed to assess local standards on maternal care and work-up following fetal death in all institutions to gain an insight into clinical practice across Austrian maternity units.

\section{Methods}

\section{Data collection}

We created a 12-item questionnaire covering demographic variables (3 items), local facilities and practice following IUFD (5 items), routine post-mortem work-up (1 item) and obstetrical care after IUFD (3 items; Additional file 1).

The demographic variables included hospital location as per Austrian federal region (categorical variable; Vienna; Lower Austria; Upper Austria; Burgenland; Styria; Carinthia; Salzburg; Tyrol; Vorarlberg), type of institution (categorical variable; secondary referral hospital; tertiary referral hospital) and annual live birth-rate (categorical variable; $\leq 500 ; 501$ - 1000; 1001 - 2000; $\geq 2001)$.

One question regarding local facilities assessed whether there is a department of pathology on-site of the hospital (dichotomous variable; yes; no) and whether the institution has a guideline on maternal care and investigations following antepartum stillbirth (dichotomous variable; yes; no). In that context, we surveyed whether there was a felt need for a national guideline on clinical management after stillbirth in Austria (dichotomous variable; yes; no).

Practice following IUFD included the question, whether the department would admit the woman for induction of labour (IOL) or whether the woman would need to be transferred to another hospital for delivery (dichotomous variable; yes; no) and whether the institution would offer a post-mortem consultation following stillbirth delivery (categorical variable; no; always; yes; if requested by the parents; if examinations were conducted; if results were suspicious/abnormal).

One question regarding routine post-mortem work-up covered the types of investigations conducted following IUFD, proposing fetal autopsy, fetal magnetic resonance imaging (MRI), placental histology, fetal genetics (e.g., chromosomal examination; microarray examination; whole exome sequencing) and source of genetic material (umbilical cord blood; amniotic fluid; fetal muscle biopsy; placental tissue), and finally maternal examinations, such as Kleihauer testing, antibody screening, blood cultures for infections, virology, urine culture, vaginal swabs, HbA1c, glucose tolerance test, thyroid function test and thrombophilia screening (categorical variables; always; under certain circumstances; never).

Finally, we surveyed obstetrical care after IUFD: Firstly, we assessed timing of admission for labour induction (categorical variable; straight after first diagnosis; on the following day; after two days; after 1 week; depending on woman's preference; others), and secondly, medication regime for IOL after fetal death (categorical variable $\leq 27^{+6}$ gestational weeks: mifepristone; misoprostol; others; $\geq 28^{+0}$ gestational weeks: mifepristone; misoprostol; dinoproston; balloon; others).

Our final variable elaborated on psychological support for affected women after IUFD (categorical variable; as an in-patient; as an outpatient; none; others).

\section{Study design}

The questionnaire was sent to all $(n=75)$ secondary and tertiary referral hospitals with a maternity unit in Austria and was accompanied by an invitation letter addressed to the head of the obstetric department and a franked response envelope. The heads of department or one of their designated consultants were asked to fill out and (anonymously) return the questionnaire. Survey time was between January and July 2019 and deadline was set after 3 months of receipt. A reminder was sent by email to the departmental director directly after 2 months.

Returned questionnaires were extracted for all variables and answers were transferred into an excel file sheet. Institutional epidemiological data were retrieved from 
the Department of Clinical Epidemiology Tirol Kliniken, Austria, and combined with our dataset. After data check for integrity and consistency, the database was frozen and made anonymous prior to final analysis.

\section{Statistical analyses}

Descriptive categorical data are given as counts (n) and percentages (\%). We compared categorical variables with $\mathrm{Chi}^{2}$ and Fisher's Exact test, respectively. Associations between variables were assessed by Pearson's correlations and $\mathrm{Chi}^{2}$ tests. Additionally, univariate binary logistic regressions were performed to assess the odds ratio (OR) and 95\% Confidence Interval (CI) for variables with more than two categories. A forest plot with a logarithmic scale (natural logarithm) illustrates the OR and 95\% CIs. All tests are two-sided, and the level of significance was set at $<0.05$. Statistical tests were performed with SPSS Statistics Version 26.0 (IBM Corporation, Armonk, NY, USA) and figures designed by GraphPad Prism 9 for macOS (GraphPad Software, LLC) and STATA (16.0, StataCorp LLC, College Station, TX).

\section{Results}

\section{Institutional demographics}

In total, 46 (61.3\%) maternity units from 37 (80.4\%) secondary and $9(19.6 \%)$ tertiary referral hospitals, respectively, participated in this survey. The respondents were from eight out of nine Austrian federal states [5 (10.9\%) units from the capital Vienna; 16 (34.8\%) from Lower Austria; 8 (17.4\%) from Upper Austria; 6 (13.0\%) from Tyrol; 4 (8.7\%) from Styria; 3 (6.5\%) from Vorarlberg; 2 (4.3\%) from Salzburg and 2 (4.3\%) from Carinthia].
Annual live birth rate was $\leq 500$ in $5(10.9 \%)$ participating hospitals, 501-1000 in 18 (39.1\%) hospitals, 1001-2000 in 14 (30.4\%) hospitals and $\geq 2001$ in $9(19.6 \%)$ hospitals.

\section{Presence of institutional guidelines}

$17(37.0 \%)$ maternity units [13 (35.1\%) secondary vs. 4 (44.4\%) tertiary referral hospitals] replied to have an institutional guideline on maternal care and investigations following stillbirth, whilst the majority of units $(n=29 ; 63.0 \%)$ responded to have none [24 (64.9\%) secondary vs. 5 (55.6\%) tertiary hospitals; Fig. 1].

Independent of the local implementation of an institutional guideline, 26 (56.5\%) departments [22 (84.6\%) secondary vs. 4 (44.4\%) tertiary referral hospitals] consider a national guideline important and necessary, whilst 13 (28.3\%) denied and 7 (15.2\%) did not disclose their interest.

The effect of demographic variables and local clinical standards on the implementation of an institutional guideline is illustrated in Fig. 2. Whilst we found that, in our cohort, most maternity units with institutional guidelines were more likely to conduct post-mortem follow-up consultations with the parents after fetal death $[n=12$; $\left.70.6 \% ; X^{2}(7 ; 40)=14.205 ; p=0.007\right]$, regression analysis indicated that follow-up consultations, scheduled only in case of suspicious or abnormal test results, were associated with lower odds for presence of an institutional guideline [OR 0.133 (95\% CI 0.018-0.978); $p=0.047$ ].

We also observed a trend in favour for a guideline with respect to the type of institution (i.e., university clinic), the presence of an affiliated pathology department, the recognition of the importance of psychological support,

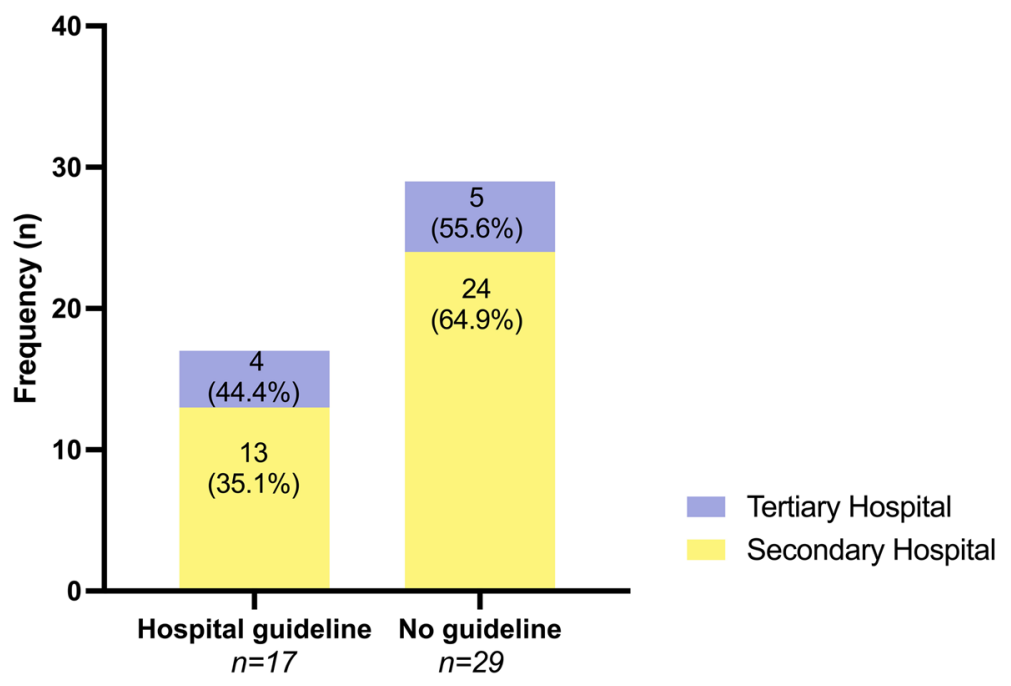

Fig. 1 Presence of an institutional guideline on maternal care and investigations following stillbirth in Austrian secondary and tertiary referral hospitals (total $n=46$ ) 


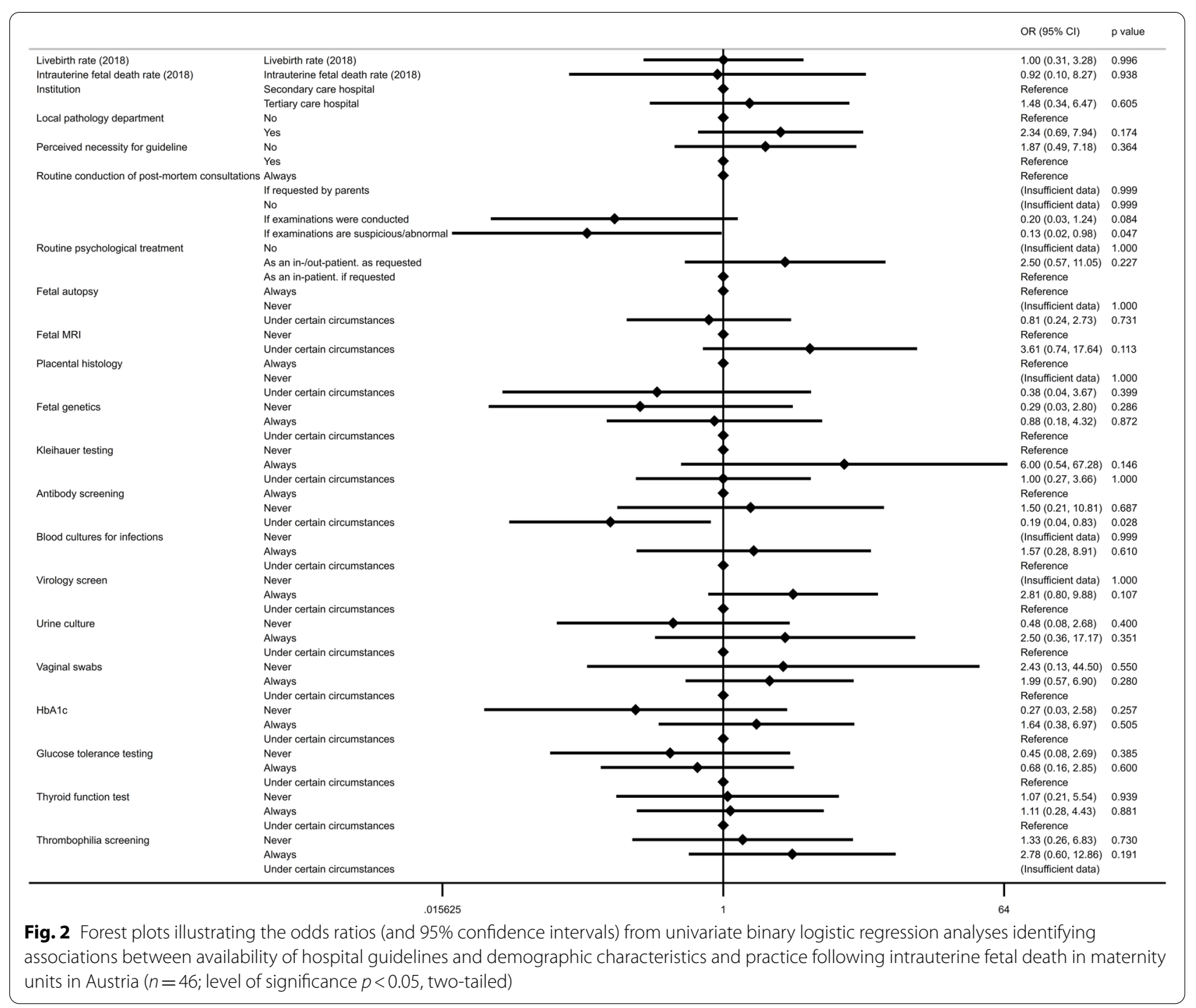

and the regular performance of post-mortem investigations, such as maternal screening for thrombophilia, diabetes or infection, though these effects did not reach statistical significance (Fig. 2).

\section{Clinical practice on maternal care and investigations}

\section{Admission}

Following diagnosis of fetal death, all maternity units $(n=46 ; 100 \%)$ would arrange IOL at their place. 19 $(41.3 \%)$ units [16 (43.2\%) secondary vs. 3 (33.3\%) tertiary referral hospitals] would usually have the women decide when to be admitted to hospital for IOL. 8 (17.4\%) units [6 (16.2\%) secondary vs. 2 (22.2\%) tertiary hospitals] usually admit the woman straight after diagnosis of fetal death, whereas $12(26.1 \%)$ units [10 (27.0\%) secondary vs. $2(22.2 \%)$ tertiary hospitals] arrange re-admission on the subsequent day, 3 (6.5\%) institutions [2 (5.4\%) secondary vs. 1 (11.1\%) tertiary hospitals] on the following day or the day after, and 4 (8.7\%) units [3 (8.1\%) secondary vs. 1 (11.1\%) tertiary referral hospitals] after two days, as long as the woman remains clinically stable.

\section{Methods for induction of labour}

Across surveyed maternity units, most common regimen for IOL between $24^{+0}$ and $27^{+6}$ gestational weeks is mifepristone on admission day (i.e., Day 1), followed by misoprostol from second day onwards (Fig. 3). Above $28^{+0}$ gestational weeks, most institutions would induce their patients using the pharmacological substances misoprostol (31.9\%) and dinoprostone (37.2\%; Fig. 4). 


\section{Regimen for labour induction after fetal death at $24^{+0}-27^{+6}$ weeks}

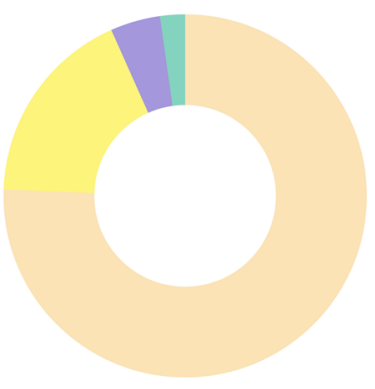

75.6\% Mifepristone (Day 1) + Misoprostol (Day 2)

$17.8 \%$ Misoprostol only

$4.4 \%$ Misoprostol only (Day 1) \pm Mifepristone only

$2.2 \% \quad$ Nalador only

Total $=45$

Fig. 3 Regimen of induction of labour following antepartum stillbirth between $24^{+0}$ and $27^{+6}$ gestational weeks across Austrian maternity units (multiple entries per institution possible)

Regimen for labour induction after fetal death $\geq 28^{+0}$ weeks

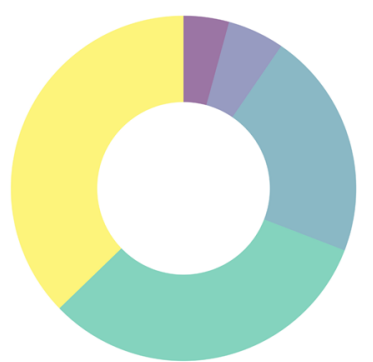

Total $=94$

\section{3\% Mifepristone only}

$5.3 \%$ Cervical balloon

21.2\% Mifepristone (Day 1) + Misoprostol (Day 2)

$31.9 \%$ Misoprostol only

$37.2 \%$ Dinoprostone only
Dinoprostone

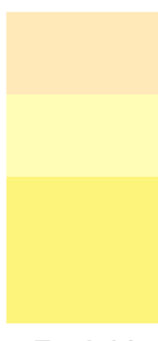

Total $=\mathbf{3 4}$
Misoprostol

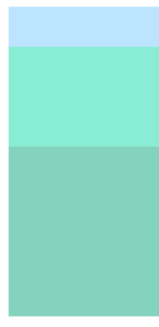

Total $=\mathbf{3 1}$

Fig. 4 Regimen of induction of labour following antepartum stillbirth above $28^{+0}$ gestational weeks across Austrian maternity units (multiple entries perinstitution possible)

\section{Investigations following antepartum stillbirth}

In $21(45.7 \%)$ surveyed hospitals [13 (35.1\%) secondary vs. $8(88.9 \%)$ tertiary referral hospitals], a local pathology department is on site, whilst the majority of hospitals have none [24 (64.9\%) secondary vs. 1 (11.1\%) tertiary hospitals]. In Austria, presence of a local pathology department strongly correlates with the type of hospital $(p=0.003)$ and annual hospital live birth rate $(p=0.039)$. Also, hospitals with an integrated pathology department would perform fetal genetic tests following stillbirth more often, than units with no integrated pathology department ( $p=0.017)$.

Maternity units, which usually admit the woman immediately after diagnosis of fetal death, are more likely 
to perform maternal tests to rule out clotting or bleeding disorders, such as thrombophilia $(p=0.03)$ and occult feto-maternal haemorrhage by Kleihauer-Betke test $(p=0.049)$.

Table 1 summarizes all types of conducted maternal, placental and fetal post-mortem examinations following fetal death, independent of availability of an institutional guideline, and compares their frequency between secondary and tertiary care hospitals. Whilst $44.4 \%$ of tertiary referral hospitals consider requesting a fetal MRI after fetal death, $89.2 \%$ of secondary referral hospitals would never request such $(p=0.036)$. Likewise, significantly more tertiary referral hospitals would initiate chromosomal and microarray analyses following fetal death, than secondary referral hospitals $(44.4 \%$ vs. $19.4 \%$; $p=0.016)$. No other significant differences in regular post-mortem examinations were observed between secondary and tertiary referral hospitals.

In summary, across Austrian maternity units, the three most commonly conducted investigations following antepartum stillbirth are placental histology (20.9\%), fetal autopsy (13.1\%) and maternal antibody screen (11.5\%; Fig. 5). Fetal autopsy was strongly linked to fetal genetic analyses $(p=0.015)$ and placental histology $(p=0.031)$, yet was independent of a local pathology department $(p=0.341)$ and type of institution $(p=0.451)$.

Psychological support All, but one surveyed maternity units would routinely offer professional psychological support to affected parents whilst hospitalized, and 9 (19.6\%) departments [6 (16.2\%) secondary vs. 3 (33.3\%) tertiary referral hospitals] would also arrange psychological follow-up consultations as an outpatient.

Post-mortem follow-up consultations 16 (34.8\%) units [12 (32.4\%) secondary vs. 4 (44.4\%) tertiary hospitals] replied to always schedule a regular post-mortem followup consultation with the parents following antepartum stillbirth, whilst 7 (15.2\%) units [5 (13.5\%) secondary vs. $2(22.2 \%)$ tertiary hospitals] would never arrange such. In 8 (17.4\%) units [6 (16.2\%) secondary vs. 2 (22.2\%) tertiary referral hospitals] post-mortem consultations would only be scheduled, if post-mortem investigations had been conducted. In 7 (15.2\%) units, follow-up consultations would only be arranged in case of suspicious or abnormal test results, and in 2 (4.3\%) institutions, only if requested by the parents. $6(13.0 \%)$ units did not declare their practice after stillbirth.

\section{Discussion}

In the absence of national clinical practice guidelines on maternal care and investigations following antepartum stillbirth in Central Europe, this is the first survey to investigate the implementation of institutional protocols in Austrian hospitals. With a response rate of 61 percent covering for $73 \%$ of all registered stillbirths and $64 \%$ of all registered live births in this country, exceeding the average response rate in postal surveys in healthcare professionals, [11] our survey provides a representative overview on practice and position.

As only a small proportion of hospitals had implemented local guidelines on maternal care and investigations following stillbirth, the robustness of our analyses to recognize obvious influential factors supporting such protocol was small. Whilst we observed a trend in favour for tertiary referral hospitals, affiliated pathology departments, and hospitals, which routinely offer psychological support during hospitalisation, we clearly found that units that only perform follow-up consultations in case of abnormal post-mortem investigations only, were less likely to have implemented an institutional guideline. After all, we have identified a common need for a national protocol, which may accelerate the implementation of such guideline by respective societies in the near future.

Interestingly, independent of the presence of a local guideline, we found that placental histology, fetal autopsy and maternal antibody screening were the three most common investigations requested after fetal death. In the United Kingdom (UK), fetal post-mortem examinations are carried out in about $44 \%$ of stillbirths, [12] and in the United States, the uptake of autopsy has been reported as low as $35 \%$ in tertiary care centres and $13 \%$ in community hospitals [13]. After all, autopsy and placental histology are considered the gold standards following fetal loss, as they give insight into the aetiology in $22-76 \%$ of the cases $[14,15]$.

Our study is not devoid of limitations inherent to the failure to control for recall bias of responders and thus data accuracy from returned questionnaires, potentially limiting their validity. As over half of the responding institutions showed a lack of a local guideline, yet their support for a national protocol, we cannot rule out a certain degree of selection bias. Also, hospitals with small numbers of stillbirths might not have participated in this survey. Furthermore, we have not included the post-mortem assessment of fetal carboxy-haemoglobin as a marker for chronic hypoxia related to maternal nicotine abuse, despite the prevalence of daily smoking habits in $27.5 \%$ of the Austrian female population aged 30 and 45 years [16]. Finally, our data might not be generalizable and translatable to other countries due to divergent facilities and different medico-legal practice following perinatal death. These limitations confirm the need to gain insight into care and practice following stillbirth in other European countries, too, to further strengthen our findings. 
Table 1 Summary on spectrum and frequency of performed fetal, placental and maternal post-mortem examinations following fetal death in secondary and tertiary care hospitals $(n=46)$ across Austria (frequency n; percentage \%) and comparison of frequency between types of hospital (two-sided Fisher's Exact test; level of significance $p<0.05$ )

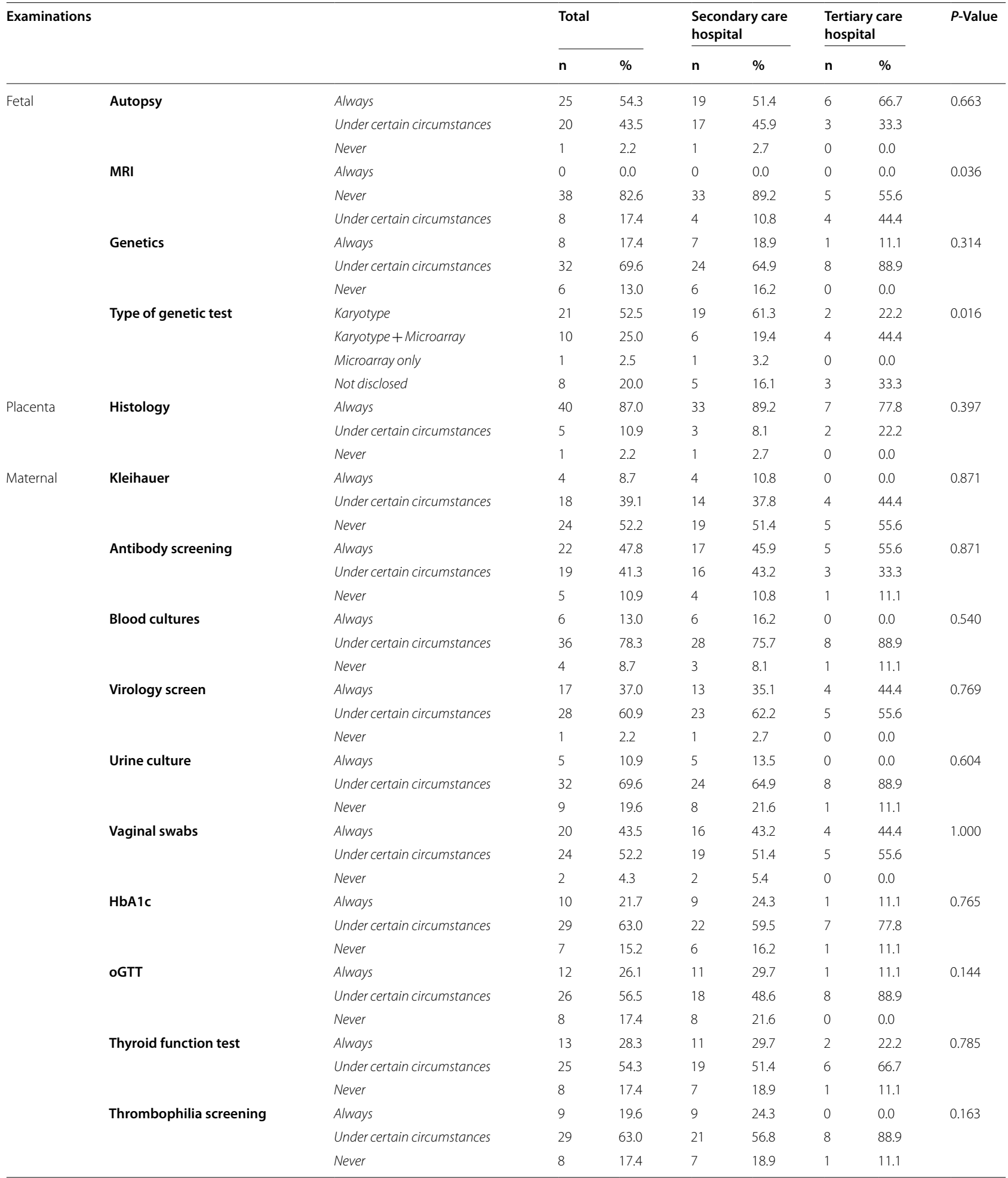




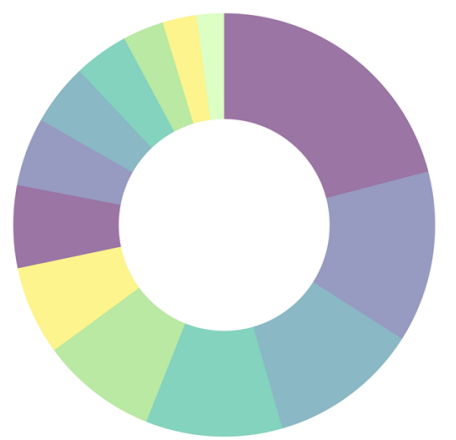

$\begin{array}{ll}20.9 \% & \text { Placental histology } \\ 13.1 \% & \text { Fetal autopsy } \\ 11.5 \% & \text { Antibody screen } \\ 10.5 \% & \text { Vaginal swabs } \\ 8.9 \% & \text { Virology } \\ 6.8 \% & \text { Thyroid function test } \\ 6.3 \% & \text { oGTT } \\ 5.2 \% & \text { HbA1c } \\ 4.7 \% & \text { Thrombophilia screen } \\ 4.2 \% & \text { Fetal genetics } \\ 3.1 \% & \text { Blood culture } \\ 2.6 \% & \text { Urine culture } \\ 2.1 \% & \text { Kleihauer }\end{array}$

Fig. 5 Overview on post-mortem examinations always performed after fetal death in maternity units, which took part in this survey

Despite these limitations, the high response rate in our survey results in a representative overview on clinical practice across the country [11]. Of note, all obstetric departments from medical university clinics participated in our survey, which demographically yield the highest numbers of annual stillbirth deliveries. Furthermore, the majority of returned questionnaires were fully completed, thus limiting the number of missing data. The absence of a formal local guideline does not rule out any other form of standard practice within an institution, as habits may be verbally shared and communicated within a team. The strength of the questionnaire was to capture these practices and provide an overview on clinical care in a costeffective, reliable and versatile manner. The combination of institutional data from questionnaires with epidemiological data from the Austrian Birth Registry allowed us to interpret the results with greater detail by adjusting for the numbers of live and stillbirths per institution.

Clinical Practice Guidelines are "statements that include recommendations intended to optimize patient care" [17]. Whilst their aim is to enhance the medical practice of doctors and guide them along with evidencebased knowledge towards better patients' care,[18] studies have likewise revealed poor adherence in cases where guidelines are not based upon good evidence,[19] lead to over-treatment rather than "effective" treatment of a patient,[20] or when conflicts of interests of authors create a bias in clinical recommendations [21, 22]. Defining the cause of death helps bereaved parents in their grieving process, $[23,24]$ estimates the recurrence risk in future pregnancies, serves mortality statistics and future public health interventions to reduce the number of perinatal loss [25]. Elucidating the cause and underlying risk factors through thorough and concise post-mortem investigations may therefore prevent future losses.

Evidence-based clinical practice guidelines on maternal and fetal post-mortem examinations therefore ought to be implemented in every hospital in order to optimize, standardize and harmonize their practice according to national guidelines such a supported by the RCOG, PSANZ or ACOG with the aim of finding the cause of fetal death and improve maternal care in subsequent pregnancies. Ideally, sensitivity of post-mortem examinations should be high with a low inter-rater variability in result interpretation in order to determine the underlying aetiology with high accuracy $[8,26]$. Placental histopathology, fetal autopsy and fetal genetic testing are considered the gold standards following stillbirth [27]. Known barriers to post-mortem examinations, however, are considered parents' dislike of invasiveness, poor communication and lack of understanding of the purpose [28]. Contrarily, parents' desire for more information acts as a facilitator and it therefore lies within the responsibility of the caring obstetrician to propose the optimal postmortem workup after stillbirth in a respectful way to bereaved parents. Obstetricians most commonly consent bereaved parents for perinatal autopsy, yet about $12.4 \%$ claim to lack training in counselling, after all [29].

Although the annual stillbirth rate has held stable at around 3.1 cases per 1000 live births beyond 24 gestational weeks for the last 12 years, in Austria,[1] a reduction of $10-15 \%$ by 2025 is desirable. In the UK, the annual stillbirth rate of 4.7 per 1000 live births ranks among the highest in Europe, which led the UK Department of Health and Social Care support the National Health Service to reduce the stillbirth rates by $50 \%$ by 2025. In 2015, the national prevention program "Saving Babies' Lives Care Bundle" has been introduced, comprising four measures: (a) reduction of smoking in pregnancy, (b) assessment of risk and surveillance in growth restricted fetuses, (c) raising awareness of reduced fetal movements and (d) effective monitoring during labour [30]. Subsequently, UK hospitals had to implement local maternity guidelines in order to follow these steps towards better maternal and fetal care and prevention of stillbirth. A recent study evaluated the local practice 
guidelines from 75 participating UK hospitals and found that whilst only the minority of $5.6 \%$ of evaluated guidelines were recommended for clinical use and $75 \%$ needed some modifications, $16.7 \%$ were not recommended at all [31]. Assessment of staff opinions on the use of their clinical guidelines revealed that over half considered the guidelines to offer higher quality care to women, yet $30 \%$ of staff claimed not to be able to follow their guidelines due to time issues, while $24 \%$ were not able to implement their recommendations at all. These limitations clearly indicate that the quality, content and perceived utility of guidelines need to be addressed internationally.

\section{Conclusion}

This national survey reveals that less than half of the surveyed maternity units have implemented an institutional guideline on maternal care and investigations following antepartum stillbirth, irrespective of annual live and stillbirth rate or type of referral centre. Independent of the implementation of a local guideline, there is a perceived need for a national guideline, which may ensure highest level of care and optimal post-mortem work-up following antepartum stillbirth across the country.

\section{Abbreviations}

IUFD: Intrauterine fetal death; MRI: Magnetic resonance imaging; ACOG: American College of Obstetrics and Gynecology; Cl: Confidence Interval; IOL: Induction of labour; OR: Odds ratio; PSANZ: Perinatal Society of Australia and New Zealand; RCOG: Royal College of Obstetricians and Gynaecologists; UK: United Kingdom.

\section{Supplementary Information}

The online version contains supplementary material available at https://doi. org/10.1186/s12884-021-03995-z.

Additional file 1. 12-item questionnaire sent out to 75 maternity units in Austria between January and July 2019 (Translated from German into English).

\section{Acknowledgements}

We sincerely thank all who participated in this survey and supported us in sharing their experience of care and practice at their institutions. DAM acknowledges the intellectual input from Prof. Dr. H. Helmer, the statistical review by E.L. Meyer, PhD and the support from Prof. DDr. J.C. Huber.

\section{Authors' contributions}

DAM: Design of the work; data acquisition, data analysis, interpretation of data; drafted the work and substantively revised it. SN: Data acquisition, data analysis, interpretation of data; substantively revised the work. VR: Design of the work; data acquisition; substantively revised the work. HL: Data acquisition, data analysis, interpretation of data. SL: Design of the work; data acquisition, data analysis. PWH: Design of the work; data acquisition. HK: Design of the work; data acquisition. PK: Design of the work; data acquisition; substantively revised the work. Each author has made substantial contributions to the conception and has approved the submitted version and has agreed both to be personally accountable for the author's own contributions and to ensure that questions related to the accuracy or integrity of any part of the work, even ones in which the author was not personally involved, are appropriately investigated, resolved, and the resolution documented in the literature.

\section{Funding}

This research did not receive any specific grant from funding agencies in the public, commercial, or not-for-profit sectors.

\section{Availability of data and materials}

The datasets used and analysed during the current study are available from the corresponding author on reasonable request.

\section{Declarations}

\section{Ethics approval and consent to participate}

The study was approved by the Ethics Committee of the Medical University of Vienna ( $3^{\text {rd }}$ August 2018) and complied with the principles as outlined in the declaration of Helsinki. Participants gave formal written consent to participate in the study by their response.

\section{Consent for publication}

Not applicable.

\section{Competing interests}

The authors declare that they have no competing interests.

\section{Author details}

${ }^{1}$ Department of Obstetrics and Gynecology, Division of Feto-Maternal Medicine, Medical University of Vienna, Waehringer Guertel 18-20, 1090 Vienna, Austria. ${ }^{2}$ Department of Clinical Epidemiology, Tyrolean Federal Institute for Integrated Care, Tirol Kliniken GmbH, Anichstraße 35, 6020 Innsbruck, Austria. ${ }^{3}$ Austrian Society of Obstetrics and Gynecology, Frankgasse 8, 1090 Vienna, Austria.

Received: 6 November 2020 Accepted: 9 July 2021

Published online: 24 July 2021

\section{References}

1. Statistik Austria. Demographics on Austrian Population - Livebirths and Stillbirths 2020. Available from: http://www.statistik.at/web_de/stati stiken/menschen_und_gesellschaft/bevoelkerung/geborene/index.html.

2. EURO-Peristat. Stillbirth and infant death rates are decreasing, but still vary widely across Europe 26 November 2018. Available from: http:// www.europeristat.com/images/Euro-Peristat-UK-press-release_FINAL.pdf.

3. Lamont K, Scott NW, Jones GT, Bhattacharya S. Risk of recurrent stillbirth: systematic review and meta-analysis. BMJ (Clinical research ed). 2015;350:h3080 PubMed PMID: 26109551. Epub 2015/06/26. eng.

4. MBRRACE-UK. Saving Lives, Improving Mothers' Care- Lessons learned to inform maternity care from the UK and Ireland Confidential Enquiries into Maternal Deaths and Morbidity 2015-17 Nov 2019. Available from: http:// www.npeu.ox.ac.uk/assets/downloads/mbrrace-uk/reports/MBRRACE-UK Maternal Report 2019 - WEB VERSION.pdf.

5. World Health Organization. Maternal, newborn, child and adolescent health: Stillbirth 2019. Available from: http://www.who.int/maternal_ child_adolescent/epidemiology/stillbirth/en/.

6. Qaseem A, Forland F, Macbeth F, Ollenschläger G, Phillips S, Wees Pvan der. Guidelines International Network: toward international standards for clinical practice guidelines. Ann Int Med. 2012;156(7):525-31 PubMed PMID: 22473437. Epub 2012/04/05. eng.

7. American College of Obstetricians and Gynecologists. ACOG Practice Bulletin Clinical Management Guidelines No. 102. 2009.

8. Royal College of Obstetricians and Gynaecologists. Late Intrauterine Fetal Death and Stillbirth Green-top Guideline No. 55. 2010.

9. Perinatal Society of Australia and New Zealand Investigation of Stillbirths. Second Edition, Version 2.2 ed2009.

10. Perinatal Society of Australia and New Zealand. Clinical Practice Guideline for Care Around Stillbirth and Neonatal Death, Version 3.1, March 2018.

11. Cook JV, Dickinson HO, Eccles MP. Response rates in postal surveys of healthcare professionals between 1996 and 2005: An observational study. 
12. Confidential Enquiry into Maternal and Child Health. Confidential Enquiry into Maternal and Child Health. Perinatal Mortality 207. 2009.

13. Heuser CC, Hunn J, Varner M, Hossain S, Vered S, Silver RM. Correlation between stillbirth vital statistics and medical records. Obstetr Gynecol. 2010;1 16(6):1296-301 PubMed PMID: 21099594. Epub 2010/11/26. eng.

14. Gordijn SJ, Erwich JJ, Khong TY. Value of the perinatal autopsy: critique. Pediatr Dev Pathol. 2002;5(5):480-8 PubMed PMID: 12202996.

15. Downe S, Kingdon C, Kennedy R, Norwell H, McLaughlin MJ, Heazell AE. Post-mortem examination after stillbirth: views of UK-based practitioners. Eur J Obstetr Gynecol Reprod Biol. 2012;162(1):33-7 PubMed PMID: 22397745. Epub 2012/03/09. eng.

16. Silver RM, Varner MW, Reddy U, Goldenberg R, Pinar H, Conway D, et al. Work-up of stillbirth: a review of the evidence. Am J Obstetr Gynecol. 2007;196(5):433-44 PubMed PMID: 17466694. Pubmed Central PMCID: 2699761.

17. Clinical Practice Guidelines We Can Trust. In: Graham R, Mancher M, Miller Wolman D, Greenfield S, Steinberg E, editors. Clinical Practice Guidelines We Can Trust. Washington DC: 2011 by the National Academy of Sciences; 2011. p. 25-6.

18. Kuehn BM. IOM sets out "gold standard" practices for creating guidelines, systematic reviews. Jama. 2011;305(18):1846-8 PubMed PMID: 21558510. Epub 2011/05/12. eng.

19. Angell M. Industry-sponsored clinical research: a broken system. Jama. 2008;300(9):1069-71 PubMed PMID: 18768418. Epub 2008/09/05. eng.

20. Pogach $L$, Aron DC. Sudden acceleration of diabetes quality measures. Jama. 2011;305(7):709-10 PubMed PMID: 21325188. Epub 2011/02/18. eng.

21. Guyatt G, AkI EA, Hirsh J, Kearon C, Crowther M, Gutterman D, et al. The vexing problem of guidelines and conflict of interest: a potential solution. Ann Int Med. 2010;152(11):738-41 PubMed PMID: 20479011. Epub 2010/05/19. eng.

22. Rothman DJ, McDonald WJ, Berkowitz CD, Chimonas SC, DeAngelis CD, Hale RW, et al. Professional medical associations and their relationships with industry: a proposal for controlling conflict of interest. Jama. 2009;301(13):1367-72 PubMed PMID: 19336712. Epub 2009/04/02. eng

23. Kirkley-Best E, Kellner KR. The forgotten grief: a review of the psychology of stillbirth. Am J Orthopsychiatry. 1982;52(3):420-9 PubMed PMID: 7114170.

24. Burden C, Bradley S, Storey C, Ellis A, Heazell AE, Downe S, et al. From grief, guilt pain and stigma to hope and pride - a systematic review and meta-analysis of mixed-method research of the psychosocial impact of stillbirth. BMC Pregnancy Childbirth. 2016;19(16):9 PubMed PMID: 26785915. Pubmed Central PMCID: 4719709.

25. Flenady V, Wojcieszek AM, Middleton P, Ellwood D, Erwich JJ, Coory $M$, et al. Stillbirths: recall to action in high-income countries. Lancet. 2016;387(10019):691-702 PubMed PMID: 26794070. Epub 2016/01/23. eng.

26. Man J, Hutchinson JC, Heazell AE, Ashworth M, Levine S, Sebire NJ. Stillbirth and intrauterine fetal death: factors affecting determination of cause of death at autopsy. Ultrasound Obstetr Gynecol. 2016:48(5):56673 PubMed PMID: 27781317.

27. Page JM, Christiansen-Lindquist L, Thorsten V, Parker CB, Reddy UM, Dudley DJ, et al. Diagnostic tests for evaluation of stillbirth: results from the stillbirth collaborative research network. Obstetr Gynecol. 2017;129(4):699-706 PubMed PMID: 28333795. Epub 2017/03/24. eng.

28. Lewis C, Hill M, Arthurs OJ, Hutchinson C, Chitty LS, Sebire N. Factors Affecting Uptake of Postmortem Examination in the Prenatal, Perinatal and Paediatric Setting; a Systematic Review. BJOG : an international journal of obstetrics and gynaecology. 2017 Feb 11. PubMed PMID: 28190300.

29. Heazell AE, McLaughlin MJ, Schmidt EB, Cox P, Flenady V, Khong TY, et al. A difficult conversation? The views and experiences of parents and professionals on the consent process for perinatal postmortem after stillbirth. BJOG. 2012;119(8):987-97 PubMed PMID: 22587524. Epub 2012/05/17. eng.

30. National Health Service (NHS). Saving Babies'Lives Version Two: A care bundle for reducing perinatal mortality 15 March 2019 [updated 16 September 2020; cited 2020]. Available from: http://www.england.nhs. uk/publication/saving-babies-lives-version-two-a-care-bundle-for-reduc ing-perinatal-mortality/.

31. Lau YZ, Widdows K, Roberts SA, Khizar S, Stephen GL, Rauf S, et al. Assessment of the quality, content and perceived utility of local maternity guidelines in hospitals in England implementing the saving babies' lives care bundle to reduce stillbirth. BMJ Open Qual. 2020;9(2):e000756 PubMed PMID: 32327423. Pubmed Central PMCID: PMC7254132. Epub 2020/04/25. eng.

\section{Publisher's Note}

Springer Nature remains neutral with regard to jurisdictional claims in published maps and institutional affiliations.
Ready to submit your research? Choose BMC and benefit from:

- fast, convenient online submission

- thorough peer review by experienced researchers in your field

- rapid publication on acceptance

- support for research data, including large and complex data types

- gold Open Access which fosters wider collaboration and increased citations

- maximum visibility for your research: over $100 \mathrm{M}$ website views per year

At BMC, research is always in progress.

Learn more biomedcentral.com/submissions 